\title{
Age-Associated Changes in Skeletal Muscle Regeneration: Effect of Exercise
}

\author{
Teet Seene*, Priit Kaasik \\ Institute of Exercise Biology and Physiotherapy, University of Tartu, Tartu, Estonia \\ Email: ${ }^{*}$ teet.seene@ut.ee
}

Received 24 September 2015; accepted 18 November 2015; published 23 November 2015

Copyright (C) 2015 by authors and Scientific Research Publishing Inc.

This work is licensed under the Creative Commons Attribution International License (CC BY). http://creativecommons.org/licenses/by/4.0/

(c) ()) Open Access

\begin{abstract}
Aim of the present short review is to provide a comprehensive update on age-associated skeletal muscle damage, regeneration, and effect of endurance and resistance type of exercise training on muscle regeneration. Decrease in muscle quantity and quality leads to disability in the aging population. The degradation rate of muscle proteins during aging increased about two times, and muscle strength and motor activity decreased at the same time. Aging induced sarcopenia is a result of decreased synthesis and increased degradation of muscle proteins, which leads to the slower turnover rate of these proteins, especially contractile proteins, and this, in turn, leads to the decrease in muscle strength. Muscle damage is mainly caused by excessive strain in contracting fibre and aging muscle is particularly sensitive to it. The decreased synthesis and increased degradation rate of contractile proteins are in accordance with the increase destructive processes in muscle and lead to the decrease in the regeneration capacity and development of sarcopenia in the elderly. Exercise training increases muscle mass, oxidative capacity, contracile quality, regeneration capacity and via this, physiological functioning of skeletal muscle is improved in the elderly.
\end{abstract}

\section{Keywords}

Aging, Muscle Damage, Regeneration, Exercise

\section{Introduction}

Aging is a physiological process that includes a gradual decrease in skeletal muscle mass, strength, and endurance coupled with an ineffective response to tissue damage [1]. Aging and a reduced physical level are mainly responsible for the progressive decline in several physiological capacities in the elderly [2]. Decrease in the protein synthesis rate is affected by the translational process occurring in older human skeletal muscle,

"Corresponding author. 
whereas the transcriptional process appears to be unaltered when compared with those in younger men [3]. Skeletal muscle fibers have a remarkable capacity to regenerate [3] [4], and this depends on the number of satellite cells under the basal lamina of fibers and their oxidative capacity [5]. Autografting of skeletal muscle in old rodents shows that regeneration proceeds at a significantly slower rate in comparison with young animals [6]. A decrease in the number of satellite cells has been shown in fast-twitch muscle fibers of elderly subjects [7]. In sarcopenic muscle, the decrease in the satellite cell pool and the length of telomeres might explain the higher prevalence of muscle injuries and delayed muscle regeneration [2]. Functionally heterogeneous satellite cells with different properties may be recruited for different tasks, for example, muscle regeneration [8]-[10]. After severe damage, muscles in old rodents did not regenerate as well as muscles in adults [6]. The decreased regeneration capacity of muscles has shown due to extrinsic causes rather than an intrinsic limitation of muscles, but it is a combination of both extrinsic and intrinsic factors that contribute to reduced skeletal muscle regeneration [11] [12]. A contraction-induced muscle injury to weightbearing muscles in old rodents causes deficits in muscle mass and force [13]. The degradation rate of contractile proteins in rat skeletal muscle during aging increased about two times, and muscle strength and motor activity decreased at the same time [14]. Aging induced sarcopenia is a result of decreased synthesis and increased degradation of myofibrillar proteins, which leads to the slower turnover rate of muscle proteins, especially contractile proteins, and this, in turn, leads to the decrease in muscle strength [14]-[16]. Increasing dietary protein intake in combination with the use of anabolic agents attenuates muscle loss [15]. In essence, sarcopenia is an imbalance between protein synthesis and degradation rate [17].

Effective exercise training in the elderly increases both muscle oxidative capacity and contractile property, enhancing their life quality by improving muscle functional capacity and plasticity.

The aim of this review is to provide a comprehensive update on age-associated skeletal muscle damage and regeneration, effect of endurance and resistance type of exercise training and to analyze the mechanisms which underly muscle damage and regeneration.

\section{Muscle Weakness in Elderly}

During aging the physical system suffers to a different extent and rate in diverse parts of the body. This results in reduced functional reserve, a decrease in vital capacity, deterioration of the capillaty blood supply, and a decrise of muscle mass [18].

Sarcopenia has been considered to be a minor modifiable risk factor for health outcomes, and it plays a significant role in the etiology of disability [19] [20]. Aging and inactivity or disuse is associated with a decline in muscle mass, structure, and strength [15] [21]. A sedentary lifestyle, bed rest, spaceflight, and hindlimb suspension lead the skeletal muscle to microcirculatory disturbances, atrophy, protein loss, changes in contractile properties, and fibertype switching [15] [22]-[24]. In both young and aged skeletal muscle, oxidative stress increases in response to inactivity [25] and may have an important role in mediating muscle atrophy. Inactivity results in a decrease in the number of myonuclei and an increase in the number of apoptotic myonuclei in skeletal muscle [26]. Heat-shock protein (HSP) 70 inhibits caspase-dependent and caspaseindependent apoptotic pathways and may function in the regulation of muscle size via the inhibition of necrotic muscle fiber distribution and apoptosis in aged muscle [27]. The decline in elderly muscle mass primarily results from type II fiber atrophy and loss in the number of these muscle fibers (Figure 1). Increased variability in fiber size, accumulation of nongrouping, scattered, and angulated fibers, and the expansion of extracellular space are characteristics of muscle atrophy [28]. Beyond the loss of muscle size due to reduced fiber number and myofibrillar proteins that underlie muscle weakness in the elderly [29], impairments in neural activation have been found, as well as potential alterationsin other muscular properties that may reduce contractile quality defined as a reduction in involuntary force production per unit muscle size [30]-[32]. The functional and structural decline of the neuromuscular system is a recognized cause of decreased strength, impaired performance of daily activities, and loss of independence in the elderly [33]. Loss of muscle strength in older adults is weakly associated with the loss of lean body mass [34]. It means that muscle weakness in older adults is more related to impairments in neural activation and/or reductions in the intrinsic force generating capacity of skeletal muscle [33].

\section{Muscle Damage}

Certain intracellular mechanisms are associated with muscle damage both in young and old, such as calcium 


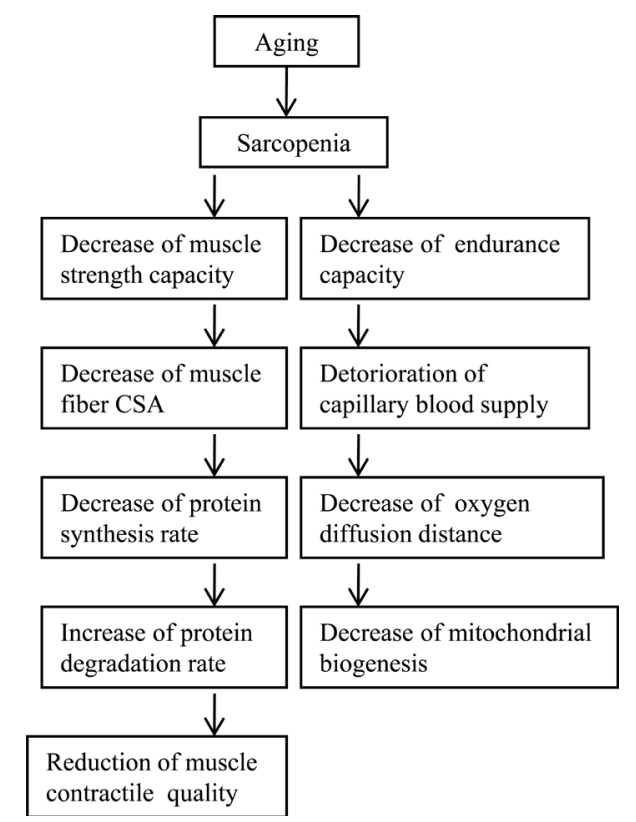

Figure 1. Effect of aging on skeletal muscle.

CSA: cross sectional area.

overload, free radical formation and a decrease in energy supply. A fall in cellular adenosine triphosphate (ATP) content is associated with apoptosis and muscle ATP levels can decrease in response to stress [35]. The release of cellular proteins occurs when cellular ATP falls below a critical level, and interference in the energy supply to the muscle membrane is an important factor leading to enzyme efflux [36] [37]. The ability to alter mitochondrial content and function is an important adaptive response of the skeletal muscle. Skeletal muscle regeneration is accompanied by a marked stimulation of mitochondrial biogenesis concomitant with the onset of muscle fibre differentiation [38].

Muscle damage during exercise increases energy and protein needs [39]. Contracting muscle fibres release cytokines, which in turn create many effects in other organs, including the brain. Sooner or later, all these different mechanisms create sensations of fatigue and exhaustion in the mind of the exercising subject [40]. Long lasting exercise induces an anti-inflammatory effect in skeletal muscle, especially in fast twitch (FT) muscle fibres and a pro-inflammatory effect in adipose tissue [41]. This effect contributes to increased lipolysis to provide energy for the exercising muscle. Cytokines play an important role in the exercise induced immune reaction and exercise related metabolic and cellular signal transduction, and they are also capable of increasing HSP synthesis [42]. It is possible that HSP may act as a cytokine in reaction to long lasting exercise, stimulate tumour necrosis factor-alpha (TNF- $\alpha$ ), interleukin (IL)- $\beta$, and IL-8 in monocytes, and activate CD 14-dependent and $\mathrm{Ca}^{2+}$-dependent pathways [43]. Leukemia inhibitory factor (LIF) has been shown as a trauma factor for injured skeletal muscle due to its myotrophic action and in response to muscle injury together with IL-6 they are upregulated in injured muscle fibres and mononuclear cells at the site of the muscle injury [44]. High concentration of pro-inflammatory cytokine TNF- $\alpha$ promotes damage and impairs skeletal muscle [44]. Exercise caused muscle damage in elderly is more related with muscle fibers with low oxidative capacity.

\section{Endurance Training Caused Muscle Damage}

Endurance exercise training (ET) results in regulation of enzyme systems of Krebs cycle, electron trsnsport chain, capillary supplay, changes in key metabolic enzymes involved in fatty acid activation, and increased oxygen uptake [45]. ET does not result in hypertrophy of skeletal muscle fibers involved in the exercise response because the level of force production is relatively small compared to their maximal force-generating [46]. ET causes most changes in type I and IIA muscle fibres (Figure 2). The day following ET, significant destructive changes are in the myofibrils of these fibers. This damage includes the destruction of myosin and actin filaments and the disturbance of the regularity of Z-disc in some sarcomeres [47]. In some A-discs, myosin 
filaments are absent and the destruction may cover the whole sarcomere. These structural changes are in accordance with biochemical ones [48]. Small structural rearrangements take place in type IIB fibres during ET as these fibers are less recruited. The number of mitochondria in type IIB fibers during ET does not increase significantly; they are located in small groups near nuclei and between myofibrils on the level of Z-disc, but not in each sarcomere [49]. As oxidative capacity of skeletal muscle decreasas in the elderly, endurance exercise has shown to be effective in its restoration as it stimulates mitochondrial biogeneses (Figure 2) and improves their functional parameters [50]. The higher oxidative capacity in trained elderly people is related to an increase in the abilities of cardiovascular system and to the lesser extent to an increase in muscle mitochondrial concentration [51]. Under conditions of hypoxia the connection between mitochondria and sarcomeres are disturbed as sarcomeric components disintegrate the muscle fiber structure and cause cell injury and death [52]. Aging and reduced physical level are responsible for the decline in several physiological capacities in the elderly. The degradation of muscle contractile proteins increased about two times in aging induced sarcopenic muscle, protein synthesis rate, muscle strength and motor activity decreased at the same time [14]. During adaptation of skeletal muscle to the ET changes in isform composition of main muscle contractile protein myosin, points to the transformation of the contractile apparatus in accordance with the increase in muscle oxidative capacity [53]. During the adaptation of elderly skeletal muscle to the ET these changes in FT skeletal muscle points to the transformation of the muscle contractile apparatus in accordance with the increase in muscle oxidative capacity. This adaptational process shows coordination between changes in oxidative capacity and contractile apparatus in skeletal muscle during adaptation to ET primarily in relation to muscle metabolism [54].

\section{Resistance Training Caused Muscle Damage}

Resistance training (RT) cause an increase in the cross-sectional area (CSA) of the whole muscle and individual muscle fibers, and an increase in myofibrillar size and number (Figure 2). The hypertrophy response is related to activation of satellite cells in the early stages of training [55]. Structural changes in skeletal muscle during RT

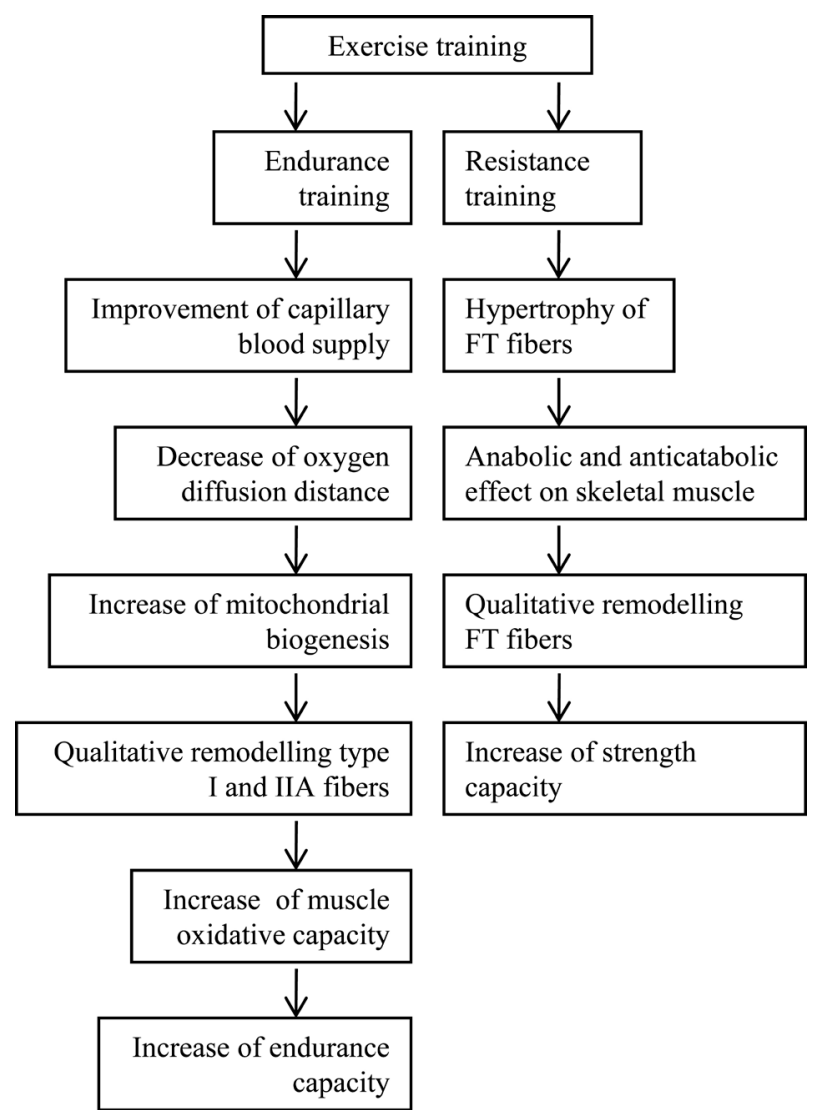

Figure 2. Effect of exercise training on aging muscle. 
are fibre specific. FT fibres are more vulnerable to damage than slow-twitch (ST) [56]. In RT, type IIX/IIB fibres have twisted myofibrils in a relatively small area and they have lost connection with the neighbouring structures [49]. Damage caused by RT in skeletal muscle is also stimulus for regeneration due to muscle growth and promoting signalling events arising from the mechanical deformation of fibres, hormones and immune/ inflammatory responses. The focal denervation of muscle fibers during exercise is reversable and accompanied by by regeneration of new axonal terminals growing into pre-existing synaptic grooves. RT enhances the synthesis rate of myofibrillar proteins, not of sarcoplasmic proteins, and this is related to the mammalian target of rapamycin complex by activating proteins with mitogen activated protein kinase signalling [57]. Structural changes with exercise induced muscle damage are associated with the influence of gene expression strengthening the muscle, protecting the tissue against further injury [58], and an increased protein turnover rate [49]. RT increased the synthesis rate of myofibrillar proteins in ageing FT muscle. The slowdown of the turnover rate of contractile proteins with age approximately one third is caused both by the decreased protein synthesis rate and the intensification of the protein degradation rate. Although mechanical activity changes the turnover rate of contractile proteinsin both young and old, the turnover rate changes in old age are relatively slower than than in young.

\section{Muscle Regeneration}

Under the basal lamina, skeletal muscle contains quiescent mononucleated cells-satellite cells (Sc) characterized by their high level of Pax7 expression. Sc which soon after muscle damage activate, divide, proliferate, undergo myogenic differentiation, maturation and form new muscle fibres [59] [60]. Sc, which develop into myoblasts, contain a lot of ribosomes, branching granular sarcoplasmic reticulum with widened canals and a well developed Golgi apparatus [49]. Sometimes Sc also contain centrioles, which confirms that these cells are divided by mitosis. In some of these Sc, sarcoplasm close to the nucleus contains bundles of filaments, which may turn out to be myofilamets [61].

Many growth factors are produced in injured skeletal muscle (Figure 3) and influence its regeneration [60] [62]. Leukaemia inhibitory factor (LIF) stimulates skeletal muscle Sc proliferation and is involved in muscle hypertrophy and regeneration during exercise [63]. Peroxisome proliferator activated receptor isoform $\delta$ (Ppar $\delta$ ) gene, which regulates skeletal muscle oxidative capacity via Sc proliferation [64] as well as injury induced myokine insulin-like 6 (Insl6) [65] also support muscle regeneration.

The fact that Sc play a direct role in fast-to-slow fibre transition shows that considerable adaptive capacity resides in myonuclei [66]. The location of Sc in the postsynaptic region is evidence of the plastic regenerative capacity of this region [49]. If necessary, this kind of cells can join the muscle fibres and increase the area of the

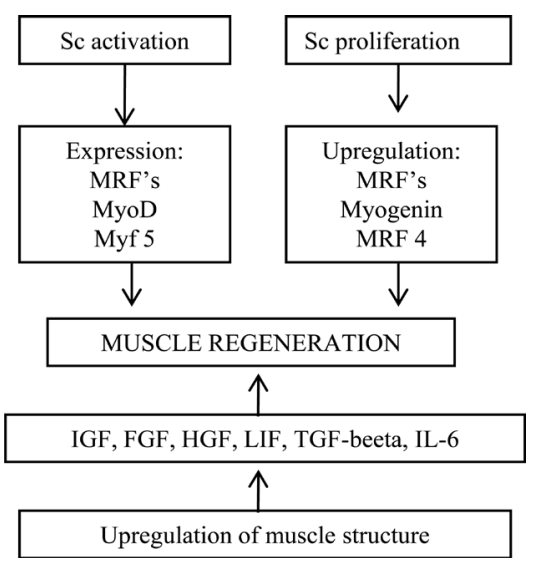

Figure 3. Regulation of damaged skeletal muscle regeneration. Exercise stimulates muscle regeneration process via Sc fusion with damaged fibers, or the formation of new muscle fibers as a result of myoblasts' fusion in order to maintain myonuclear domain size.

Sc: satellite cells; MRFs: muscle regulatory factors; MyoD: myoblast determination protein; Myf 5: myogenetic factor; MRF 4: myogenic regulatory factor; IGF: insulin-like growth factor; FGF: fibroblasts growth factor; HGF: hepatocyte growth factor; LIF: leukemia inhibitory factor; TGF: transforming growth factor; IL: interleukin. 
synapse and the number of nuclei in the region. ST oxidative muscle fibres contain a large number of Sc in comparison with FT glycolytic fibres [67]. In exercising muscle, Sc are able to leave the fibre and form a new population of myogenic cells and are later ready to form new muscle fibres [49]. Regeneration capacity is higher in type I and IIA muscle fibres, where the oxidative capacity and insulin stimulated glucose uptake is higher in comparison with type IIB/IIX fibres [37] [68].

\section{Effect of Endurance Training on the Muscle Regeneration}

Exercise training has the ability to influence the function of muscle fibres modifying their structure and metabolism and promoting the release of growth factors and other signalling molecules, such as nitric oxide, which work through the paracrine system to activate Sc [47]. ST oxidative (type I) muscle fibres contain a large number of myonuclei and Sc compared with FT glycolytic (IIB) fibres [67] [69]. Fast to slow fibre transition has been shown to be associated with increases in Sc activation, content and fusion to transforming fibres, especially within the IIB fibres [70] [71]. The number of Sc in very different stages of development under the basal lamina of type I and FT oxidative-glycolytic (type IIA) muscle fibres increases during ET [47] [61] [72]. Adenosine monophosphate-activated protein kinase (AMPK) is activated in response to ET [73] and related to the metabolic adaptation of skeletal muscle both in young and old. AMPK function includes glucose transport, glycogen metabolism, fatty acid oxidation and transcriptional regulation of structural muscle genes [74]. $\alpha_{1}$ isoform of AMPK is the regulator of skeletal muscle growth and $\alpha_{2}$ isoform regulates metabolic adaptation [75]. Increased mitochondrial biogeneses via AMPK is accompanied by supression of the myofibrillar protein synthesis through pathways mediated by mitogen activated protein kinase (MAPK), nuclear factor kappa B (NF- $\kappa$ B) mammalian target of rapamycin (mTOR) and tuberous sklerosis complex (TSC) [57] [76]. Insulin-like growth factor (IGF) I expression is higher in ST fibers [77] [78] and myostatin in fibers with higher oxidative capacity (type I and IIA) [79]. The components of the degradation system of muscle proteins, such as ubiquitin ligases muscle atrophy F-box (MAFbx) and muscle ring finger (MuRF) are about two fold higher in fibers with higher oxidative capacity [76] and in elderly. It was shown that the number of Sc in rat skeletal muscle increased about 3.5 times during ET [80]. Both oxidative capacity and Sc number in muscle fibers, which determine muscle regenerative capacity, are higher in young than in old muscle. Protein turnover in skeletal muscle is relatively slow, especially contractile proteins and endurance exercise training stimulates protein turnover [48]. The turnover rate of myosin heavy chain (MyHC) and myosin light chain (MyLC) isoforms provides a mechanism by which the type and amount of protein changes in accordance with the needs of the contractile machinery during adaptation to ET [81]. ET mainly increases the number of Sc under the basal lamina of type I and IIA fibres and increases the regeneration capacity of these fibres [49]. The mechanism associated with activity-induced shifts in myosin expression is the key to understanding the plasticity of skeletal muscle as the hypertrophied muscle fibre has adapted to a chronic overload via an alteration in its phenotype [82]. The mechanisms involved in regulating changes in the myosin expression and in the muscle mass may have different sensitivities to mechanical load [83].

\section{Effect of Resistance Training on the Muscle Regeneration}

RT increases the CSA of the whole muscle and individual muscle fibres, and increases myofibrillar size and number [45]. The hypertrophy response to RT is related to the activation of Sc in the early stage of training [55]. RT causes fiber hypertrophy in two ways: damged fibers regenerate as a result of the fusion with Sc [84] as it is proved by the incorporation of $3 \mathrm{H}$ thymidine into the nucleus of the muscle fiber [85], and via Sc activation under the basal lamina, devision and after that myosymplasts fuse with each other and form myotubes [86]. RT also causes other morphological adaptations, such as hyperplasia, changes in muscle fine architecture, in myofilament density and in the structures of connective tissue [55]. RT mainly causes an increase in the CSA of IIX/IIB and IIA fibres. Structural changes in skeletal muscle during RT are fibre specific. RT enhances the synthesis rate of myofibrillar proteins, not of sarcoplasmic proteins, and this is related to the mammalian target of rapamycin complex by activating proteins with mitogen activated protein kinase signalling [57]. Recovery from intensive RT caused damages is slower as a result of age, whereas there are no age related differences in recovery from less damaging metabolic fatigue [86]. Recovery from RT, during which the power of exercise increases less than 5\% per session, causes hypertrophy of both FT and ST muscle fibres and an increase in the myonuclear number. This is achieved via Sc fusion with damaged fibres or the formation process of new muscle 
fibres as a result of myoblasts' fusion in order to maintain myonuclear domain size [85]. RT increases the level of IGF-I and mechano-growth factor (MGF) in skeletal muscle and these factors support faster recovery of muscle tissue [37].

\section{Conclusion}

The decreased synthesis and increased degradation rate of contractile proteins are in accordance with the increase destructive processes in muscle and lead to the decrease in the regeneration capacity and development of sarcopenia in elderly. Muscle damage is mainly caused by excessive strain in contracting fibre and aging muscle is particularly sensitive to it. Several factors play a role in injured skeletal muscle and influence its regeneration. So, LIF stimulates skeletal muscle Sc proliferation and is involved in muscle hypertrophy and regeneration during exercise. Ppar $\delta$ gene, which regulates skeletal muscle oxidative capacity via Sc proliferation, and injury induced myokine Insl6 also support muscle regeneration. Oxidative muscle fibres contain a large number of myonuclei and Sc compared with glycolytic fibres. The number of Sc under the basal lamina of type I and type IIA muscle fibres increases during ET and these cells are in very different stages of development. Sc number also increases during RT. The paired box transcription factor Pax7 plays a critical role in regulating the specification of Sc and in maintaining the Sc population via selfrenewal process. An increase in Sc is related to several factors expressing different genes and FT muscle hypertrophy. IGF-I have a role in the hypertrophy of muscle fibres through the stimulation of the differentiation of Sc. The MGF level increases with the increase in the number of Sc in muscle fibres during RT. Mitochondrial biogenesis increases during ET via AMP-activated AMPK which is accompanied by suppression of the myofibrillar protein synthesis through pathways mediated by MAPK and NF-kB. As a result of exercise training muscle fibres with higher oxidative capacity contain more Sc, myonuclei, mitochondria, mRNA, and have higher total ribosomal RNA content. IGF-I expression is also higher in ST fibres. Myostatin, the expression inhibitor of muscle hypertrophy, is higher in FT IIB fibres. The proteasome-, lysosome- and $\mathrm{Ca}^{2+}$-mediated protein degradation is more intensive in fibres with higher oxidative capacity during and after exercise training. The components of the degradation system of muscle proteins, such as ubiquitin ligases MAFbx and MuRF, are higher in muscle fibres with higher oxidative capacity. Both oxidative capacity and Sc number in muscle fibres play an important role in skeletal muscle regeneration. Muscle protein synthesis and degradation are balanced in ET so that fibre size does not increase. ET improves the energetic potential of skeletal muscle and supports the effective functioning of the myofibrillar apparatus. Activation of AMPK in response to ET includes an induction of glucose transport, glycogen metabolism, fatty acid oxidation and transcriptional regulation of structural genes and $\alpha_{1}$ isoform of AMPK, which regulates skeletal muscle growth. This work adds an essential contribution to the understanding of physicians and exercise therapists about the effect of character of exercise training on aging muscle, its regeneration capacity and mechanisms of regulation.

\section{Acknowledgements}

This study was supported by the funds of the Ministry of Education and Research of the Republic of Estonia, research project number TKKSB 1787. We would like to thank Piret Pärsim for technical expertise.

\section{Author Contributions}

Teet Seene and Priit Kaasik designed, participated in interpretation of data and final approval of the manuscript.

\section{Disclosure Statement}

The authors declare no conflict of interest.

\section{References}

[1] Degenes, H. and Alway, S.E. (2006) Control of Muscle Size during Disuse, Disease, and Aging. International Journal of Sports Medicine, 27, 94-99. http://dx.doi.org/10.1055/s-2005-837571

[2] Kadi, F. and Ponsot, E. (2010) The Biology of Satellite Cells and Telomeres in Human Skeletal Muscle: Effects of Aging and Physical Activity. Scandinavian Journal of Medicine and Science in Sports, 20, 39-48.

http://dx.doi.org/10.1111/j.1600-0838.2009.00966.x 
[3] Roberts, M.D., Kerksick, C.M., Dalbo, V.J., Hassell, S.E., Tucker, P.S. and Brown, R. (2010) Molecular Attributes of Human Skeletal Muscle at Rest and after Unaccustomed Exercise: An Age Comparison. Journal of Strength and Conditioning Research, 24, 1161-1168. http://dx.doi.org/10.1519/JSC.0b013e3181da786f

[4] Bassaglia, Y. and Gautron, J. (1995) Fast and Slow Rat Muscles Degenerate and Regenerate Differentlya after Cruch Injury. Journal of Muscle Research and Cell Motility, 16, 420-429. http://dx.doi.org/10.1007/BF00114507

[5] Shultz, E. and Darr, K. (1990) The Role of Satellite Cells in Adaptive or Induced Fiber Transformations. In: Pette, D., Ed., The Dynamic State of Muscle Fibers, W. de Gruyter, Berlin, 667-681.

[6] Kaasik, P., Aru, M., Alev, K. and Seene, T. (2012) Aging and Regenerative Capacity of Skeletal Muscle in Rats. Current Aging Science, 5, 126-130. http://dx.doi.org/10.2174/1874609811205020126

[7] Verney, J., Kadi, F., Charifi, N., Feasson, L., Saafi, M.A., Castells, J., Piehl-Aulin, K. and Denis, C. (2008) Effects of Combined Lower Body Endurance and Upper Body Resistance Training on the Satellite Cell Pool in Elderly Subjects. Muscle \& Nerve, 38, 1147-1154. http://dx.doi.org/10.1002/mus.21054

[8] Malatesta, M., Perdoni, F., Muller, S., Pellicciari, C. and Zancanaro, C. (2010) Pre-mRNA Processing Is Partially Impaired in Satellite Cell Nuclei from Aged Muscles. Journal of Biomedicine \& Biotehnology, 2010, Article ID: 410405.

[9] Ono, Y., Boldrin, L., Knopp, P., Morgan, J.E. and Zammit, P.S. (2010) Muscle Satellite Cells Are a Functionally Heterogeneous Population in Both Somite-Derived and Branchiomeric Muscles. Development Biology, 337, 29-41. http://dx.doi.org/10.1016/j.ydbio.2009.10.005

[10] Tatsumi, R. (2010) Mechano-Biology of Skeletal Muscle Hypertrophy and Regeneration: Possible Mechanism of Stretch-Induced Activation of Resident Myogenic Stem Cells. Animal Science Journal, 81, 11-20. http://dx.doi.org/10.1111/j.1740-0929.2009.00712.x

[11] Carlson, B.M., Dedkov, E.I., Borisov, A.B. and Faulkner, J.A. (2001) Skeletal Muscle Regeneration in Very Old Rats. The Journal of Gerontology. Series A, Biological Sciences and Medical Sciences, 56, B224-B233. http://dx.doi.org/10.1093/gerona/56.5.b224

[12] Conboy, I.M., Conboy, M.J., Wagers, A.J., Girma, E.R., Weissman, I.L. and Rando, T.A. (2005) Rejuvenation of Aged Progenitor Cells by Exposure to a Young Systemic Environment. Nature, 433, 760-764. http://dx.doi.org/10.1038/nature03260

[13] Rader, E.P. and Faulkner, J.A. (2006) Recovery from Contraction-Induced Injury Is Impaired in Weight-Bearing Muscles of Old Male Mice. Journal of Applied Physiology, 100, 656-661. http://dx.doi.org/10.1152/japplphysiol.00663.2005

[14] Kaasik, P., Umnova, M., Pehme, A., Alev, K., Aru, M., Selart, A. and Seene, T. (2007) Ageing and Dexamethasone Associated Sarcopenia: Peculiarities of Regeneration. The Journal of Steroid Biochemistry and Molecular Biology, 105, 85-90. http://dx.doi.org/10.1016/j.jsbmb.2006.11.024

[15] Evans, W.J. (2010) Skeletal Muscle Loss: Cachexia, Sarcopenia, and Inactivity. The American Journal of Clincal Nutrition, 91, 1123S-1127S. http://dx.doi.org/10.3945/ajcn.2010.28608A

[16] Evans, W.J., Paolisso, G., Abbatecola, A.M., Corsonello, A., Bustacchini, S., Strollo, F. and Lattanzio, F. (2010) Frailty and Muscle Metabolism Dysregulation in the Elderly. Biogerontology, 11, 527-536. http://dx.doi.org/10.1007/s10522-010-9297-0

[17] Seene, T. and Kaasik, P. (2012) Muscle Weakness in the Elderly: Role of Sarcopenia, Dynapenia, and Possibilities for Rehabilitation. European Review of Aging and Physical Activity, 9, 109-117. http://dx.doi.org/10.1007/s11556-012-0102-8

[18] Mechling, H. and Netz, Y. (2009) Aging and Inactivity-Capitalizing on the Protective Effect of Planned Physical Activity in Old Age. European Review of Aging and Physical Activity, 6, 89-97. http://dx.doi.org/10.1007/s11556-009-0052-y

[19] Lauretani, F., Russo, C.R., Bandinelli, S., Bartali, B., Cavazzini, C., Di Iorio, A., Corsi, A.M., Rantanen, T., Guralnik, J.M. and Ferrucci, L. (2003) Age-Associated Changes in Skeletal Muscles and Their Effect on Mobility: An Operational Diagnosis of Sarcopenia. Journal of Applied Physiology, 9, 1851-1860. http://dx.doi.org/10.1152/japplphysiol.00246.2003

[20] Clark, B.C. and Manini, T.M. (2010) Functional Concequences of Sacropenia and Dynapenia in the Elderly. Current Opinion in Clinical Nutrition and Metabolic Care, 13, 271-276. http://dx.doi.org/10.1097/MCO.0b013e328337819e

[21] Seene, T., Kaasik, P. and Riso, E.M. (2012) Review on Aging, Unloading and Reloading: Changes in Skeletal Muscle Quantity and Quality. Archives of Gerontology and Geriatrics, 54, 374-380. http://dx.doi.org/10.1016/j.archger.2011.05.002

[22] Haus, J.M., Carrithers, J.A., Trappe, S.W. and Trappe, T.A. (2007) Collagen, Cross-Linking, and Advanced Glycation 
End Products in Aging Human Skeletal Muscle. Journal of Applied Physiology, 103, 2068-2076. http://dx.doi.org/10.1152/japplphysiol.00670.2007

[23] Trappe, T. (2009) Influence of Aging and Long-Term Unloading on the Structure and Function of Human Skeletal Muscle. Applied Physiology, Nutrition, and Metabolism, 34, 459-464. http://dx.doi.org/10.1139/H09-041

[24] Pasiakos, S.M., Vislocky, L.M., Carbone, J.W., Altieri, N., Konopelski, K., Freake, H.C., Anderson, J.M., Ferrando, A.A., Wolfe, R.R. and Rodriguez, N.R. (2010) Acute Energy Deprivation Affects Skeletal Muscle Protein Synthesis Associated Intracellular Signaling Proteins in Physically Active Adults. The Journal of Nutrition, 140, 745-751. http://dx.doi.org/10.3945/jn.109.118372

[25] Siu, P.M., Pistilli, E.E. and Alway, S.E. (2008) Age-Dependent Increase in Oxidative Stress in Gastrocnemius Muscle with Unloading. Journal of Applied Physiology, 105, 1695-1705. http://dx.doi.org/10.1152/japplphysiol.90800.2008

[26] Leeuwenburgh, C., Gurley, C.M., Strotman, B.A. and Dupont-Versteegden, E.E. (2005) Age-Related Differences in Apoptosis with Disuse Atrophy in Soleus Muscle. American Journal of Physiology. Regulatory Integrative and Comparative Physiology, 288, R1288-R1296. http://dx.doi.org/10.1152/ajpregu.00576.2004

[27] Ogata, T., Machida, S., Oishi, Y., Higuchi, M. and Muraoka, I. (2009) Differential Cell Death Regulation between Adult-Unloaded and Aged Rat Soleus Muscle. Mechanisms of Ageing and Development, 130, 328-336. http://dx.doi.org/10.1016/j.mad.2009.02.001

[28] Buford, T.W., Anton, S.D., Judge, A.R., Marzetti, E., Wohlgemuth, S.E., Carter, C.S., Leeuwenburgh, C., Pahor, M. and Manini, T.M. (2010) Models of Accelerated Sarcopenia: Critical Pieces for Solving the Puzzle of Age-Related Muscle Atrophy. Ageing Research Reviews, 9, 369-383. http://dx.doi.org/10.1016/j.arr.2010.04.004

[29] Clark, B.C. and Manini, T.M. (2008) Sarcopenia $\neq$ Dynapenia. The Journal of Gerontology. Series A, Biological Sciences and Medical Sciences, 63, 829-834. http://dx.doi.org/10.1093/gerona/63.8.829

[30] Gonzales, E., Messi, M.L. and Delbono, O. (2000) The Specific Force of Single Intact Extensor Digitorum Longus and Soleus Mouse Muscle Fibers Declines with Aging. The Journal of Membrane Biology, 178, 175-183. http://dx.doi.org/10.1007/s002320010025

[31] Stackhouse, S.K., Stevens, J.E., Lee, S.C., Pearce, K.M., Snyder-Mackler, L. and Binder-Macleod, S.A. (2001) Maximum Voluntary Activation in Nonfatigued and Fatigued Muscle of Young and Elderly Individuals. Physical Therapy, 81, 1102-1109.

[32] Weisleder, N., Brotto, M., Komazaki, S., Pan, Z., Zhao, X., Nosek, T., Parness, J., Takeshima, H. and Ma, J. (2006) Muscle Aging Is Associated with Compramised $\mathrm{Ca}^{2+}$ Spark Signaling and Segregated Intracellular $\mathrm{Ca}^{2+}$ Release. The Journal of Cell Biology, 174, 639-645. http://dx.doi.org/10.1083/jcb.200604166

[33] Manini, T.M. and Clark, B.C. (2012) Dynapenia and Aging: An Update. The Journal of Gerontology. Series A, Biological Sciences and Medical Sciences, 67, 28-40. http://dx.doi.org/10.1093/gerona/glr010

[34] Gandevia, S.C. (2001) Spinal and Supraspinal Factors in Human Muscle Fatigue. Physiological Reviews, 81, 17251789.

[35] Perrey, S. and Rupp, T. (2009) Altitude-Induced Changes in Muscle Contractile Properies. High Altitude Medicine \& Biology, 10, 175-182. http://dx.doi.org/10.1089/ham.2008.1093

[36] Gibala, M. (2009) Molecular Responses to High-Intensity Interval Exercise. Applied Physiology, Nutrition, and Metabolism, 34, 428-432. http://dx.doi.org/10.1139/H09-046

[37] Seene, T., Umnova, M., Kaasik, P., Alev, K. and Pehme, A. (2008) Overtraining Injuries in Athletic Population. In: Tiidus, P.M., Ed., Skeletal Muscle Damage and Repair, Human Kinetics, Champaign, 173-184.

[38] Duguez, S., Féasson, L., Denis, C. and Freyssenet, D. (2002) Mitochondrial Biogenesis during Skeletal Muscle Regeneration. American Journal of Physiology. Endocrinology and Metabolism, 282, E802-E809. http://dx.doi.org/10.1152/ajpendo.00343.2001

[39] Lowery, L. and Forsythe, C.E. (2006) Protien and Overtraining: Potential Applications for Free-Living Athletes. Journal of the International Society of Sports Nutrition, 3, 42-50. http://dx.doi.org/10.1186/1550-2783-3-1-42

[40] Ament, W. and Verkere, G.J. (2009) Exercise and Fatigue. Sports Medicine, 39, 389-422. http://dx.doi.org/10.2165/00007256-200939050-00005

[41] Neto, J.C.R., Lira, F.S., Oyama, L.M., Zanchi, N.E., Yamashita, A.S., Batista Jr., M.L., Oller do Nascimento, C.M. and Seelaender, M. (2009) Exhaustive Exercise Causes an Anti-Inflammatory Effect in Skeletal Muscle and a Pro-Inflammatory Effect in Adipose Tissue in Rats. European Journal of Applied Physiology, 106, 697-704. http://dx.doi.org/10.1007/s00421-009-1070-1

[42] Liu, Y. and Steinacker, J.M. (2001) Changes in Skeletal Muscle Heat Shock Proteins: Pathological Significance. Frontiers in Bioscience, 6, D12-D25. http://dx.doi.org/10.2741/Liu

[43] Steinacker, J.M. and Liu, Y. (2002) Stress Proteins and Applied Exercise Physiology. In: Locke, M. and Noble, E.G., 
Eds., Exercise and Stress Response: The Role of Stress Proteins, CRC Press, Boca Raton, 197-216. http://dx.doi.org/10.1201/9781420042016.ch11

[44] Kurek, J.B., Bower, J.J., Romanella, M., Koentgen, F., Murphy, M. and Austin, L. (1997) The Role of Leukemia Inhibitory Factor in Skeletal Muscle Regeneration. Muscle \& Nerve, 20, 815-822. http://dx.doi.org/10.1002/(SICI)1097-4598(199707)20:7<815::AID-MUS5>3.0.CO;2-A

[45] Holloszy, J.O. and Booth, F.W. (1976) Biochemical Adaptations to Endurance Exercise in Muscle. Annual Review of Physiology, 38, 273-291. http://dx.doi.org/10.1146/annurev.ph.38.030176.001421

[46] Baldwin, K.M. and Haddad, F. (2002) Skeletal Muscle Plasticity: Cellular and Molecular Responses to Altered Physical Activity Paradigms. American Journal of Physical Meicine \& Rehabilitation, 81, S40-S51. http://dx.doi.org/10.1097/00002060-200211001-00006

[47] Magaudda, L., Di Mauro, D., Trimarchi, F. and Anastasi, G. (2004) Effects of Physical Exercise on Skeletal Muscle Fiber: Ultrastructural and Molecular Aspects. Basic and Applied Myology, 14, 17-21.

[48] Seene, T., Kaasik, P. and Alev, K. (2011) Muscle Protein Turnover in Endurance Training: A Review. International Journal of Sports Medicine, 32, 905-911. http://dx.doi.org/10.1055/s-0031-1284339

[49] Seene, T., Kaasik, P. and Umnova, M. (2009) Structural Rearrangements in Contractile Apparatus and Resulting Skeletal Muscle Remodelling: Effect of Exercise Training. Journal of Sports Medicine and Physical Fitness, 49, 410-423.

[50] Ljubicic, V., Joseph, A.M., Saleem, A., Uguccioni, G., Collu-Marchese, M., Lai, R.Y., Nguyen, L.M. and Hood, D.A. (2010) Transcriptional and Post-Transcriptional Regulation of Mitochondrial Biogenesis in Skeletal Muscle: Effects of Exercise and Aging. Biochimica et Biophysica Acta, 1800, 223-234. http://dx.doi.org/10.1016/j.bbagen.2009.07.031

[51] Sagiv, M., Goldhammer, E., Ben-Sira, D. and Amir, R. (2010) Factors Defining Oxygen Uptake at Peak Exercie in Aged People. European Review of Aging and Physical Activity, 7, 1-2. http://dx.doi.org/10.1007/s11556-010-0061-X

[52] Seppet, E.K., Eimre, M., Anmann, T., Seppet, E., Peet, N., Käämbre, T., Paju, K., Piirsoo, A., Kuznetsov, A.V., Vendelin, M., Gellerich, F.N., Zierz, S. and Saks, V.A. (2005) Intracellular Energetic Units in Healthy and Diseased Hearts. Experimental and Clinical Cardiology, 10, 173-183.

[53] Seene, T. and Kaasik, P. (2013) Muscle Damage and Regeneration: Response to Exercise Training. Health, 5, $136-145$. http://dx.doi.org/10.4236/health.2013.56A2020

[54] Seene, T., Kaasik, P., Alev, K., Pehme, A. and Riso, E.M. (2004) Composition and Turnover of Contractile Proteins in Volume-Overtrained Skeletal Muscle. International Journal of Sports Medicine, 25, 438-445.

http://dx.doi.org/10.1055/s-2004-820935

[55] Folland, J.P. and Williams, A.G. (2007) The Adaptations to Strength Training: Morphological and Neurological Contributions to Increased Strength. Sports Medicine, 37, 145-168. http://dx.doi.org/10.2165/00007256-200737020-00004

[56] Sjöström, M., Johansson, C. and Lorentzon, R. (1988) Muscle Pathomorphology in M. Quadericeps of Marathon Runners. Early Signs of Strain Disease or Functional Adaptation? Acta Physiologica Scandinavica, 132, 537-541. http://dx.doi.org/10.1111/j.1748-1716.1988.tb08362.x

[57] Moore, D.R., Atherton, P.J., Rennie, M.J., Tarnopolsky, M.A. and Phillips, S.M. (2011) Resistance Exercise Enhances mTOR and MAPK Signalling in Human Muscle Over That Seen at Rest after Bolus Protein Ingestion. Acta Physiologica, 201, 365-372. http://dx.doi.org/10.1111/j.1748-1716.2010.02187.x

[58] Schoenfeld, B.J. (2012) Does Exercise-Induced Muscle Damage Play a Role in Skeletal Muscle Hypertrophy? Journal of Strength and Conditioning Research, 26, 1441-1453. http://dx.doi.org/10.1519/JSC.0b013e31824f207e

[59] Mauro, A. (1961) Satellite Cell of Skeletal Muscle Fibres. The Journal of Biophysical and Biochemical Cytology, 9, 493-495. http://dx.doi.org/10.1083/jcb.9.2.493

[60] Charge, S.B. and Rudnicki, M.A. (2004) Cellular and Molecular Regulation of Muscle Regeneration. Physiological Review, 84, 209-238. http://dx.doi.org/10.1152/physrev.00019.2003

[61] Umnova, M. and Seene, T. (1991) The Effect of Increased Functional Load on the Activation of Satellite Cells in the Skeletal Muscle of Adult Rats. International Journal of Sports Medicine, 12, 501-504. http://dx.doi.org/10.1055/s-2007-1024723

[62] Grounds, M.D. (1999) Muscle Regeneration: Molecular Aspects and Therapeutic Implications. Current Opinion in Neurology, 12, 535-543. http://dx.doi.org/10.1097/00019052-199910000-00007

[63] Broholm, C. and Pedersen, B.K. (2010) Leukaemia Inhibitory Factor-An Exercise Induced Myokine. Exercise Immunology Review, 16, 77-85.

[64] Angione, A.R., Jiang, C., Pan, D., Wang, Y.X. and Kuang, S. (2011) PPAR $\delta$ Regulates Satellite Cell Proliferation and Skeletal Muscle Regeneration. Skeletal Muscle, 1, 33. http://dx.doi.org/10.1186/2044-5040-1-33 
[65] Zeng, L., Akasaki, Y., Sato, K., Ouchi, N., Izumiya, Y. and Walsh, K. (2010) Insulin-Like 6 Is Induced by Muscle Injury and Functions as a Regenerative Factor. The Journal of Biological Chemistry, 285, 36060-36069. http://dx.doi.org/10.1074/jbc.M110.160879

[66] Martins, K.J., Gordon, T., Pette, D., Dixon, W.T., Foxcroft, G.R., Maclean, I.M. and Putman, C.T. (2006) Effect of Satellite Cell Ablation on Low-Frequency-Stimulated Fast-to-Slow Fibre-Type Transitions in Rat Skeletal Muscle. The Journal of Physiology, 572, 281-294. http://dx.doi.org/10.1113/jphysiol.2005.103366

[67] Gibson, M.C. and Schultz, E. (1982) The Distribution of Satellite Cells and Their Relationship to Specific Fiber Types in Soleus and Extensor Digitorum Longus Muscles. The Anatomical Record, 202, 329-337. http://dx.doi.org/10.1002/ar.1092020305

[68] Mackrell, J.G. and Cartee, G.D. (2012) A Novel Method to Measure Glucose Uptake and Myosin Heavy Chain Isoform Expression of Single Fibers from Rat Skeletal Muscle. Diabetes, 61, 995-1003. http://dx.doi.org/10.2337/db11-1299

[69] Gibson, M.C. and Schultz, E. (1983) Age-Related Differences in Absolute Numbers of Skeletal Muscle Satellite Cells. Muscle \& Nerve, 6, 574-580. http://dx.doi.org/10.1002/mus.880060807

[70] Putman, C.T., Düsterhöft, S. and Pette, D. (2001) Satellite Cell Proliferation in Low Frequency-Stimulated Fast Muscle of Hypothyroid Rat. American Journal of Physiology. Cell Physiology, 279, C682-C690.

[71] Putman, C.T., Sultan, K.R., Wassmer, T., Bamford, J.A., Skorjanc, D. and Pette, D. (2001) Fiber-Type Transitions and Satellite Cell Activation in Low-Frequency-Stimulated Muscles of Young and Aging Rats. The Journal of Gerontology. Series A, Biological Sciences and Medical Sciences, 56, B510-B519. http://dx.doi.org/10.1093/gerona/56.12.b510

[72] Apell, H.J., Forsberg, S. and Hollmann, W. (1988) Satellite Cell Activation in Human Skeletal Muscle after Training: Evidence for Muscle Fiber Neoformation. International Journal of Sports Medicine, 9, 297-299. http://dx.doi.org/10.1055/s-2007-1025026

[73] Winder, W.W. and Hardie, D.G. (1996) Inactivation of Acetyl-CoA Carboxylase and Activation of AMP-Activated Protein Kinase in Muscle during Exercise. The American Journal of Physiology, 270, E299-304.

[74] Hardie, D.G. and Sakamoto, K. (2006) AMPK: A Key Sensor of Fuel and Energy Status in Skeletal Muscle. Physiology, 21, 48-60. http://dx.doi.org/10.1152/physiol.00044.2005

[75] McGee, S.L., Kristy, J., Mustard, D., Hardie, D.G. and Baar, K. (2008) Normal Hypertrophy Accompanied by Phosphoryation and Activation of AMP-Activated Protein Kinase $\alpha 1$ Following Overload in LKB1 Knockout Mice. The Journal of Physiology, 586, 1731-1741. http://dx.doi.org/10.1113/jphysiol.2007.143685

[76] van Wessel, T., de Haan, A., van der Laarse, W.J. and Jaspers, R.T. (2010) The Muscle Fiber Type-Fiber Size Paradox: Hypertrophy or Oxidative Metabolism? European Journal of Applied Physiology, 110, 665-694. http://dx.doi.org/10.1007/s00421-010-1545-0

[77] Bodine, S.C., Stitt, T.N., Gonzalez, M., Kline, W.O., Stover, G.L., Bauerlein, R., Zlotchenko, E., Scrimgeour, A., Lawrence, J.C., Glass, D.J. and Yancopoulos, G.D. (2001) Akt/mTOR Pathway Is a Crucial Regulator of Skeletal Muscle Hypertrophy and Can Prevent Muscle Atrophy in Vivo. Nature Cell Biology, 3, 1014-1019. http://dx.doi.org/10.1038/ncb1101-1014

[78] Stitt, T.N., Drujan, D., Clarke, B.A., Panaro, F., Timofeyva, Y., Kline, W.O., Gonzalez, M., Yancopoulos, G.D. and Glass, D.J. (2004) The IGF-1/PI3K/Akt Pathway Prevents Expression of Muscle Atrophy-Induced Ubiquitin Ligases by Inhibiting FOXO Transcription Factors. Molecular Cell, 14, 395-403. http://dx.doi.org/10.1016/S1097-2765(04)00211-4

[79] van der Vusse, G.J., Glatz, J.F., Stam, H.C. and Reneman, R.S. (1992) Fatty Acid Homeostasis in The Normoxic and Ischemic Heart. Physiological Reviews, 72, 881-940.

[80] Seene, T.L. and Umnova, M. (1992) Relations between the Changes in the Turnover Rate of Contractile Proteins, Activation of Satellite Cells and Ultra-Structural Response of Neuromuscular Junctions in the Fast-OxidativeGlucolytic Muscle Fibres in Endurance Trained Rats. Basic and Applied Myology, 2, 39-46.

[81] Alev, K., Kaasik, P., Pehme, A., Aru, M., Parring, A.-M., Selart, A. and Seene, T. (2009) Physiological Role of Myosin Light and Heavy Chain Isoforms in Fast- and Slow-Twitch Muscles: Effect of Exercise. Biology of Sport, 26, 215-234. http://dx.doi.org/10.5604/20831862.894654

[82] Pette, D. (2001) Historical Perspectives: Plasticity of Mammalian Skeletal Muscle. Journal of Applied Physiology, 90, 1119-1124.

[83] Hernandez, J.M., Fedele, M.J. and Farrell, P.A. (2000) Time Course Evaluation of Protein Synthesis and Glucose Uptake after Acute Resistance Exercise in Rats. Journal of Applied Physiology, 88, 1142-1149.

[84] Allen, D.L., Roy, R.R. and Edgerton, V.R. (1999) Myonuclear Domains in Muscle Adaptation and Disease. Muscle \& Nerve, 22, 1350-1360. http://dx.doi.org/10.1002/(SICI)1097-4598(199910)22:10<1350::AID-MUS3>3.0.CO;2-8 
[85] Seene, T., Pehme, A., Alev, K., Kaasik, P., Umnova, M. and Aru, M. (2010) Effects of Resistance Training on Fastand Slow-Twitch Muscles in Rats. Biology of Sport, 27, 221-229. http://dx.doi.org/10.5604/20831862.919347

[86] Fell, J.W. and Williams, A.D. (2008) The Effect of Aging on Skeletal-Muscle Recovery from Exercise: Possible Implications for the Aging Athlete. Journal of Aging and Physical Activity, 16, 97-115.

\section{Abbreviations}

AMPK: adenosine monophosphate-activated protein kinase

ATP: adenosine triphosphate

CSA: cross-sectional area

ET: endurance training

FT: fast-twitch

HSP: heat shock protein

IGF: insulin-like growth factor

IL: interleukin

LIF: leukemia inhibitory factor

MAFbx: ubicuitin ligases muscle atrophy F-box

MAPK: mitogen activated protein kinase

MGF: mechano growth factor

MuRF: muscle ring finger

MyHC: myosin heavy chain

MyLC: myosin light chain

mTOR: mammalian target of rapamycin

NF- $\kappa$ B: nuclear factor kappa B

Ppar: peroxisome proliferator activated

$\mathrm{RT}$ : resistance training

Sc: satellite cell

ST: slow-twitch

TNF: tumor necrosis factor

TSC: tuberous sclerosis complex 